\title{
Correction to: An Innovative Tuned Liquid Damper for Vibration Mitigation of Structures
}

\author{
Moahmmadreza Vafaei ${ }^{1}$ (D) Ali Pabarja ${ }^{2} \cdot$ Sophia C. Alih ${ }^{3}$
}

Published online: 26 May 2021

(C) Iran University of Science and Technology 2021

\section{Correction to: International Journal of Civil Engineering https://doi.org/10.1007/s40999-021-00626-8}

Previously read as: Moahmmadreza Vafaei. It should read as: Mohammadreza Vafaei. The original article has been corrected.

In the original version of this article, unfortunately the corresponding author name is misspelled as Moahmmadreza Vafaei and published incorrectly.

The original article can be found online at https:// doi.org/10.1007/s40999-021-00626-8.

Moahmmadreza Vafaei

vafaei@utm.my

Ali Pabarja

pabarja_a@yahoo.com

Sophia C. Alih

sophiacalih@utm.my

1 Faculty of Engineering, School of Civil Engineering,

Universiti Teknologi Malaysia, Johor, Malaysia

2 Department of Civil and Structural Engineering, Universiti Kebangsaan Malaysia, Kuala Lumpur, Malaysia

3 Institute of Noise and Vibration, Faculty of Engineering, School of Civil Engineering, Universiti Teknologi Malaysia, Johor, Malaysia 